\title{
Prediction of the epichlorohydrin derived cytotoxic substances from the eluent of poly(glycerol glycidyl ether) films
}

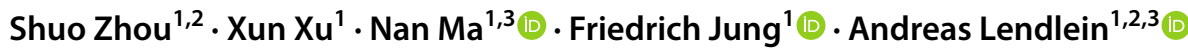

Received: 26 July 2021 / Accepted: 14 September 2021 / Published online: 13 October 2021

(c) Helmholtz-Zentrum Hereon 2021

\begin{abstract}
Glycerol-based epoxy networks have great potential for surface functionalization, providing anti-microbial and protein repellant function. However, the synthesis of glycerol glycidyl ether (GGE) monomer often requires excessive epichlorohydrin $(\mathrm{ECH})$. ECH derived organochloride containing byproducts from monomer production maybe present in the eluent of the polymer networks prepared by cationic ring-opening polymerization. Here, the cytotoxicity analysis revealed cell damages in contact with the polyGGE eluent. The occurrence of organochlorides, which was predicted based on the data from highperformance liquid chromatography/electrospray ionization mass spectrometry, as confirmed by a constant chloride level in GGE and polyGGE, and by a specific peak of $\mathrm{C}-\mathrm{Cl}$ in infrared spectra of GGE. The resulting polyGGE was densely crosslinked, which possibly contribute to the trapping of organochlorides. These results provide a valuable information for exploring the toxins leaching from polyGGE and propose a feasible strategy for minimizing the cytotoxicity via reducing their crosslink density.
\end{abstract}

\section{Introduction}

Epoxy resins, a major class of thermosetting polymers, has been widely employed in a range of biomedical applications including composite coating, biosensor manufacturing, orthopedic and dental implants for fixation and osseointegration, owing to its outstanding chemical, mechanical, electrical and adhesive features [1-5].

Recently, glycerol-based epoxy networks show great promise especially for surface functionalization to exhibit anti-biofouling potential and plasma protein resistance, which is attributed to the existence of hydroxyl groups and the polyether backbone [6-8]. Notably, the production does not require the oil-based bisphenol A, which is a key compound applied in the industrial synthesis of polyepoxides [9]. However, another oil-based substance, epichlorohydrin

Andreas Lendlein

andreas.lendlein@hereon.de

1 Institute of Active Polymers and Berlin-Brandenburg Centre for Regenerative Therapies, Helmholtz-Zentrum Hereon, Kantstr. 55, 14513 Teltow, Germany

2 Institute of Chemistry, University of Potsdam, 14476 Potsdam, Germany

3 Institute of Chemistry and Biochemistry, Free University of Berlin, 14195 Berlin, Germany
$(\mathrm{ECH})$ remains an important precursor in manufacturing glycerol glycidyl ether (GGE), which is monomer for the synthesis of polyGGE via cationic ring-opening polymerization [10-12]. Although bio-based glycerol can be used as a renewable feedstock for ECH production [13, 14], ECH residues and its organochloride derivatives are still toxic to cells and may limit the cell and tissue compatibility as well as biomedical applications of glycerol-based epoxy networks [15].

Various technologies have been applied for the cytotoxicity analysis as a prime criterion for evaluating biomaterials [16]. Chloride channels are found to express on plasma membrane to maintain the membrane homeostasis. A novel class of chloride channels predominantly presented on mitochondrial membrane plays a critical role in membrane potential regulation, mitochondrial fusion and fission [17-20]. In this regard, not only the cell viability, but also metabolic condition of mitochondria needs to be assessed when investigating the toxicity of organochloride containing compounds.

Potential toxins can be explored by computational analysis using high content imaging and deep learning, which highly rely on generating large datasets and successful machine training [21, 22]. In contrast, combining conventional analytic tools such as high-performance liquid chromatography and electrospray ionization mass spectrometry 
(HPLC-ESI-MS) for toxin prediction can be a highly effective methodological approach [23-25].

Here, the cytotoxicity analysis of the eluent of polyGGE with and without washing using organic solvents was performed. Chemical structures of potential toxic organochlorides were proposed and the underlying mechanism was illustrated based on HPLC-ESI-MS and chloride content analysis.

\section{Experimental}

Detailed descriptions appear in supplementary information.

\section{Cytotoxicity analysis of sample eluent}

Cytotoxicity analysis was performed in conformity with the EN DIN ISO standards ISO 10993-5 and ISO 1099312. PolyGGE films were washed with minimum essential medium (MEM) or solvents including acetone, chloroform and methanol (all from Sigma-Aldrich, Germany) for two weeks. The eluents of these films were then used as culture medium for L-929 cells (Manassas, USA). Total cell number and cell viability were determined by FDA/PI staining (Thermo Scientific, Germany). The cell membrane integrity was tested by LDH-assay (Roche, Germany). The metabolic activity was measured using MTS-assay (Promega, Germany).

\section{HPLC-ESI-MS}

Spectra of MEM eluent of polyGGE and pure MEM were measured with an impact II ESI-MS (Bruker Daltonics, Germany), which was connected with UltiMate 3000 HPLC (Thermo Scientific, Germany).

\section{Attenuated total reflection Fourier transform infrared (ATR-FT-IR) spectroscopy}

GGE monomer was analyzed by ATR-FT-IR spectroscopy (Nicolet IR 6700, Thermo Fisher Scientific, USA) in the absorbance range from 600 to $4000 \mathrm{~cm}^{-1}$ with a resolution of $2 \mathrm{~cm}^{-1}$.

\section{Total chloride and free chloride anion content determination}

The total chloride content of GGE and polyGGE was determined by inline combustion digestion with subsequent ion chromatography using an ion chromatograph 881 compact IC pro (Metrohm, Germany) and a combustion module with autosampler for solids. Free chloride anion content in GGE was determined according to international standard EN DIN
ISO 21627-1 using $\mathrm{AgNO}_{3}$ titration method performed on Titrino 716 DMS (Metrohm, Germany).

\section{Crosslink density determination}

Crosslink density and number average molecular weight between crosslinks of polyGGE were calculated by using the modified Flory-Rehner equation [26, 27].

\section{Results and discussion}

\section{The eluent of polyGGE films impaired the cell viability and metabolic activity}

For biomedical applications, an understanding of the toxins leaching from the polyglycerol-based networks including excessive precursors and byproducts formed during polymerization and monomer synthesis is crucial.

After $72 \mathrm{~h}$ incubation with polyGGE films, the MEM solution turned yellowish, indicating a substance being released from the polymer networks (Fig. 1a). Moreover, cells were loosely attached on the culture vessels and extensive cell lysis occurred, leaving large empty areas between individual cells (Fig. 1b). Therefore, additional washing of polyGGE films with organic solvents including acetone, chloroform and methanol was performed. Although the L-929 fibroblasts did not exhibit the typical spindle shape when exposed to eluents from polyGGE after solvent washing, the cobblestone morphology of cells suggesting a slightly improvement of culture conditions in such eluents (Fig. 1b). There was no statistical difference of the total cell density (living and dead cells) observed in the eluents of polyGGE with and without washing. However, the viability, plasma membrane integrity and mitochondrial activity were impaired, when the cells were exposed to the eluents of polyGGE with and without washing (Fig. 1c). Notably, the mitochondrial activity was rescued (sevenfold increase) when cells were cultured in the eluents of polyGGE after washing with all three solvents (Fig. 1c). Given the fact that a class of chloride channels is highly involved in organochloride mediated mitochondrial dysfunction [20], the substances more likely the organochloride containing compounds in the eluent of polyGGE are considered to be the main trigger for cytotoxicity.

\section{Prediction of chloride substances in the eluent of polyGGE via HPLC-ESI-MS}

To identify the released substances, the dissolved components of the eluent were separated by HPLC, to which an ESI-MS was coupled, which allows structural study, prediction and compound identification [28]. 

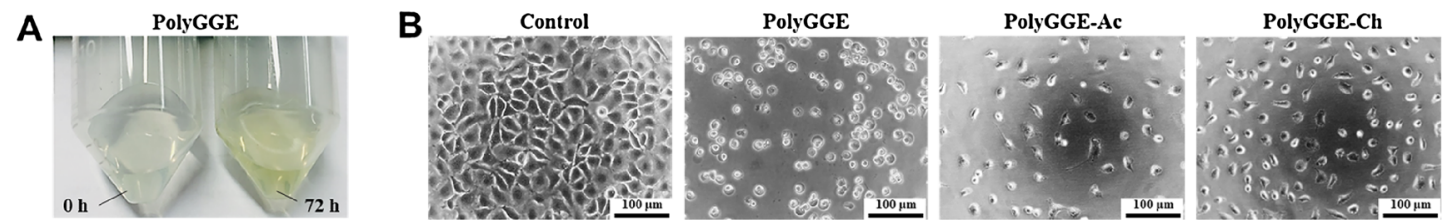

PolyGGE-Me
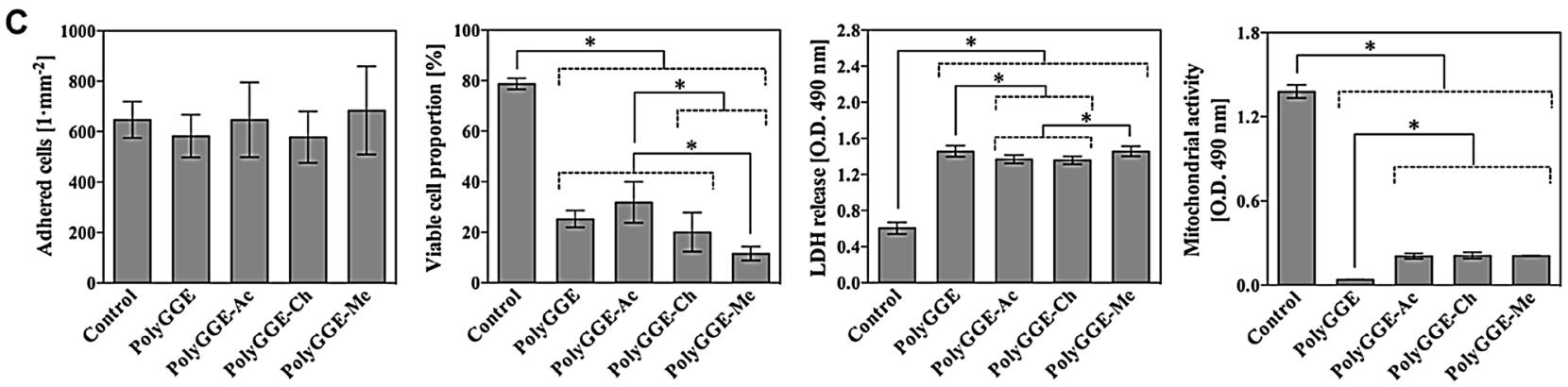

Fig. 1 Cytotoxicity analysis of eluents from polyGGE with and without washing using organic solvent. (a) The color change of eluent before $(0 \mathrm{~h})$ and after extraction $(72 \mathrm{~h})$ of polyGGE in MEM medium. (b) Representative images shown the morphological changes of L-929 cells cultured in eluents from polyGGE films with and without washing using organic solvents including acetone $(-\mathrm{Ac})$, chloroform $(-\mathrm{Ch})$ and methanol $(-\mathrm{Me})$. Scale bar $=100 \mu \mathrm{m}$. c Quantitative

Peaks in $72 \mathrm{~h}$ MEM eluent, which did not show in the pure MEM, were identified for further evaluation (Fig. 2a). $\mathrm{H}^{+}$ionized molecules with different mass-to-charge ratios $(\mathrm{m} / \mathrm{z})$ in each numbered peak could be separately distributed on the spectra. $\mathrm{H}^{+}$ionized molecules were formulated by simulating the numbered peaks at different retention time (Fig. 2b). According to the chemical formula, structures in Fig. $2 \mathrm{c}$ and d were proposed as $100 \%$ matching the $\mathrm{m} / \mathrm{z}$. Although the cleavage of $-\mathrm{C}-\mathrm{O}-\mathrm{C}-$ of polyGGE can occur driven by enzyme or bacteria to produce oligomer fragments [29], it is not likely to take place at moderate condition, as in case of MEM washing. On the contrary, those oligomers were possibly originating from the monomer. It could be seen from the ion formula $\mathrm{C}_{6} \mathrm{H}_{12} \mathrm{ClO}_{3}$, $\mathrm{C}_{9} \mathrm{H}_{18} \mathrm{ClO}_{5}$, and $\mathrm{C}_{12} \mathrm{H}_{24} \mathrm{ClO}_{7}$, when the number of chlorides is the same, $\mathrm{m} / z$ increased by 74.036 as the unit of $\mathrm{C}_{3} \mathrm{H}_{6} \mathrm{O}_{2}$. The same could be found for $\mathrm{C}_{12} \mathrm{H}_{23} \mathrm{Cl}_{2} \mathrm{O}_{6}, \mathrm{C}_{15} \mathrm{H}_{29} \mathrm{Cl}_{2} \mathrm{O}_{8}$ and for $\mathrm{C}_{12} \mathrm{H}_{24} \mathrm{Cl}_{3} \mathrm{O}_{6}, \mathrm{C}_{15} \mathrm{H}_{30} \mathrm{Cl}_{3} \mathrm{O}_{8}, \mathrm{C}_{18} \mathrm{H}_{36} \mathrm{Cl}_{3} \mathrm{O}_{10}$, which may result from the addition of $\mathrm{ECH}$ during the production of the monomer.

\section{Chlorohydrin byproducts could be formed during monomer synthesis and trapped in the polymer network}

The synthesis of the monomer GGE is generally based on the reaction between glycerol and ECH [11, 12]. When the bond between oxygen and the least substituted carbon of ECH is attacked under acid or base, 1-2-chlorohydrin intermediates

analysis of total cell density, viability, LDH release and mitochondrial activity of L-929 cells cultured in the eluents of pure MEM collected from tissue culture plate (control), polyGGE prewashed with acetone (polyGGE-Ac), chloroform (polyGGE-Ch) and methanol (polyGGE-Me). $n=8, * p<0.05$, one-way ANOVA with Tukey's tests

are formed, which undergo ring closure by base treatment companied with dechlorination. However, additive side reaction can occur. Results from HPLC-ESI-MS showed that chloride-containing substances are continuously released after intensive washing steps. These remaining chloride end groups were mainly resulting from the following conditions: (i) additional $\mathrm{ECH}$ reacts with the secondary alcohol group of the 1-2-chlorohydrin intermediate, yielding inactive $\mathrm{Cl}$ end groups (byproduct \#1), which could not be dechlorinated in the base treatment; (ii) When an acid catalyst was applied for the monomer synthesis, the bond between oxygen and the most substituted carbon of ECH could also be attacked and form 1-3-chlorohydrin (byproduct \#2 and \#3) with inactive chloride end group as byproducts, which cannot produce the epoxy ring; (iii) active $\mathrm{Cl}$ end groups (byproduct \#4) could be formed from incomplete glycidylation during ring closure reaction. However, this active $\mathrm{Cl}$ end group could be further hydrolyzed in base and form a new alcohol group (byproduct \#5). During the polymerization of polyGGE, byproducts with multi-functional groups (epoxy ring) could be involved in growing the network structure (Fig. 3a).

Although the prediction from mass spectrometry showed that $\mathrm{C}_{12} \mathrm{H}_{23} \mathrm{ClO}_{7}(\mathrm{~m} / \mathrm{z} 314.1132), \mathrm{C}_{12} \mathrm{H}_{22} \mathrm{Cl}_{2} \mathrm{O}_{6}(\mathrm{~m} / \mathrm{z}$ 332.0793) and $\mathrm{C}_{12} \mathrm{H}_{23} \mathrm{Cl}_{3} \mathrm{O}_{6}(\mathrm{~m} / 2,368.0560)$ might have the same chemical structures as byproducts \#3, \#4 and \#5, isomers from other side reactions might be also in conformity with the assigned molecular formula due to the uncontrollable random reaction between the alcohol groups and $\mathrm{ECH}$. 
A

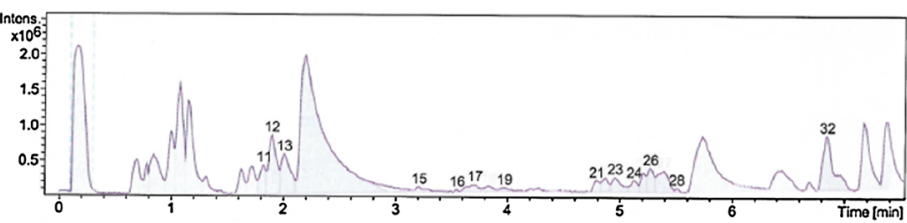

B

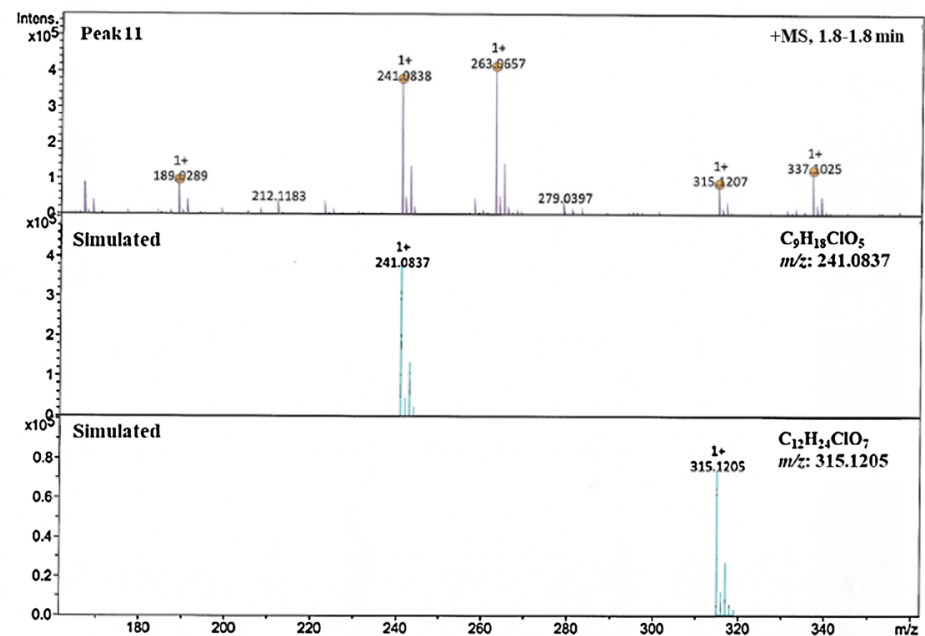

C $\mathrm{C}_{6} \mathrm{H}_{11} \mathrm{ClO}_{3}$

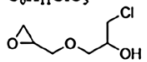<smiles>CCCCC(CC)CCC</smiles>

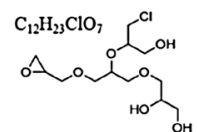

勧2

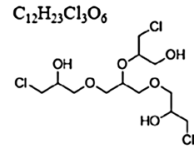

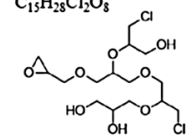

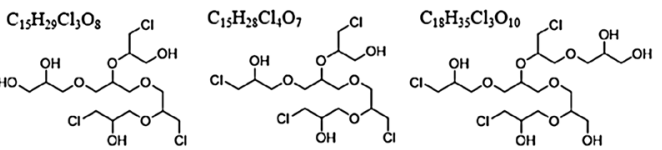

D

\begin{tabular}{|c|c|c|c|}
\hline$t_{R}(\min )$ & $m=$ & {$[\mathrm{M}+\mathrm{H}]^{+}$} & Assigned compounds \\
\hline $1.8-1.8$ & $\begin{array}{l}167.0471 \\
241.0838 \\
315.1207\end{array}$ & $\begin{array}{l}\mathrm{C}_{6} \mathrm{H}_{12} \mathrm{ClO}_{3} \\
\mathrm{C}_{9} \mathrm{H}_{18} \mathrm{ClO}_{5} \\
\mathrm{C}_{12} \mathrm{H}_{24} \mathrm{ClO}_{7}\end{array}$ & $\begin{array}{l}\mathrm{C}_{6} \mathrm{H}_{11} \mathrm{ClO}_{3}(m /=166.0397) \\
\mathrm{C}_{9} \mathrm{H}_{17} \mathrm{ClO}_{5}(m / z 240.0765) \\
\mathrm{C}_{12} \mathrm{H}_{23} \mathrm{ClO}_{7}(m / z 314.1132)\end{array}$ \\
\hline 4.8-4.9 & $\begin{array}{l}333.0867 \\
407.1234\end{array}$ & $\begin{array}{l}\mathrm{C}_{12} \mathrm{H}_{23} \mathrm{Cl}_{2} \mathrm{O}_{6} \\
\mathrm{C}_{15} \mathrm{H}_{29} \mathrm{Cl}_{2} \mathrm{O}_{5}\end{array}$ & $\begin{array}{l}\mathrm{C}_{12} \mathrm{H}_{22} \mathrm{Cl}_{2} \mathrm{O}_{6}(\mathrm{~m} / \mathrm{z} 332.0793) \\
\mathrm{C}_{15} \mathrm{H}_{28} \mathrm{Cl}_{2} \mathrm{O}_{3}(\mathrm{~m} / \mathrm{2} / \mathrm{406.1161)}\end{array}$ \\
\hline $5.1-5.2$ & $\begin{array}{l}443.1001 \\
517.1370\end{array}$ & $\begin{array}{l}\mathrm{C}_{15} \mathrm{H}_{30} \mathrm{Cl}_{3} \mathrm{O}_{8} \\
\mathrm{C}_{18} \mathrm{H}_{36} \mathrm{Cl}_{3} \mathrm{O}_{10}\end{array}$ & $\begin{array}{l}\mathrm{C}_{15} \mathrm{H}_{29} \mathrm{Cl}_{3} \mathrm{O}_{8}(m /=442.0928) \\
\mathrm{C}_{18} \mathrm{H}_{35} \mathrm{Cl}_{3} \mathrm{O}_{10}(m /=516.1296)\end{array}$ \\
\hline $5.3-5.4$ & 369.0635 & $\mathrm{C}_{12} \mathrm{H}_{24} \mathrm{Cl}_{3} \mathrm{O}_{6}$ & $\mathrm{C}_{12} \mathrm{H}_{23} \mathrm{Cl}_{3} \mathrm{O}_{6}(\mathrm{~m} /=368.0560)$ \\
\hline $6.8-6.9$ & 461.0661 & $\mathrm{C}_{15} \mathrm{H}_{29} \mathrm{Cl}_{4} \mathrm{O}_{7}$ & $\mathrm{C}_{15} \mathrm{H}_{28} \mathrm{Cl}_{4} \mathrm{O}_{7}(\mathrm{~m} /=460.0589)$ \\
\hline
\end{tabular}

Fig. 2 Prediction of organochloride containing substances in the eluent of polyGGE based on HPLC-ESI-MS analysis. (a) HPLC chromatogram of composites in polyGGE eluent compared to pure medium. Numbers indicate the peaks that were not present in the analysis of the pure medium. (b) MS spectra of peak 11 at reten- tion time of $1.8 \mathrm{~min}$, isotope patterns of $\mathrm{H}^{+}$ionized $\mathrm{C}_{9} \mathrm{H}_{18} \mathrm{ClO}_{5}$ and $\mathrm{C}_{12} \mathrm{H}_{24} \mathrm{ClO}_{7}$. Predicted chemical structures (c) and assignment of organochloride containing compounds in respect to their $\mathrm{H}^{+}$ionized forms, retention times $\left(t_{\mathrm{R}}\right)$ and mass-to-charge ratios $(\mathrm{m} / \mathrm{z})(\mathbf{d})$ in the eluent from polyGGE
A

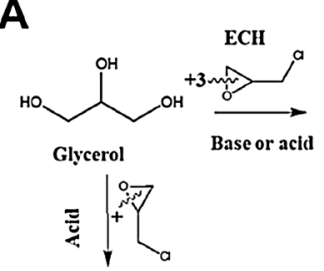<smiles>OCC(CO)OC(CO)CCl</smiles>

Byproduct \#2

(ii) 1-3-chlorohydrin formation

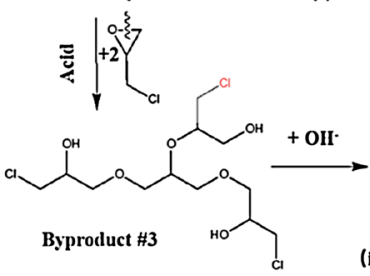

(i) addtional ECH reached with secondary alcohol groups
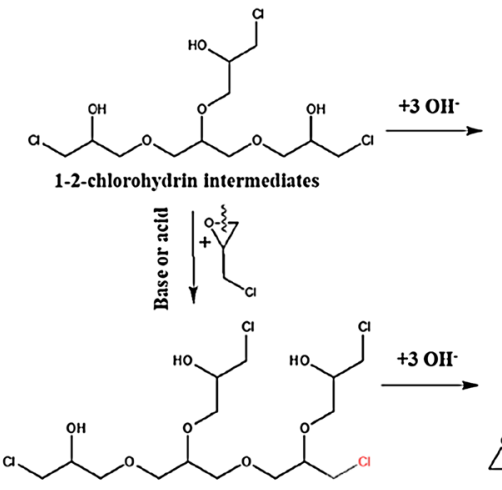

additional

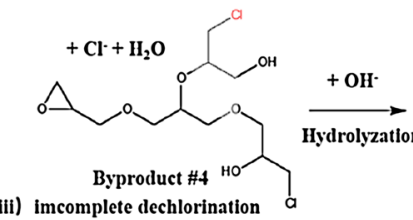

(iii) imcomplete dechlorination a

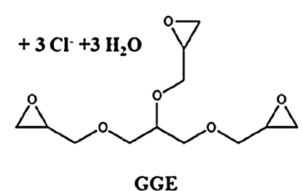

GGE

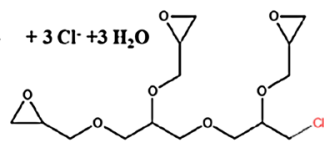

Byproduct \#1

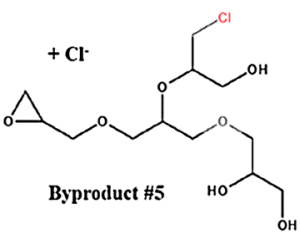

B i)
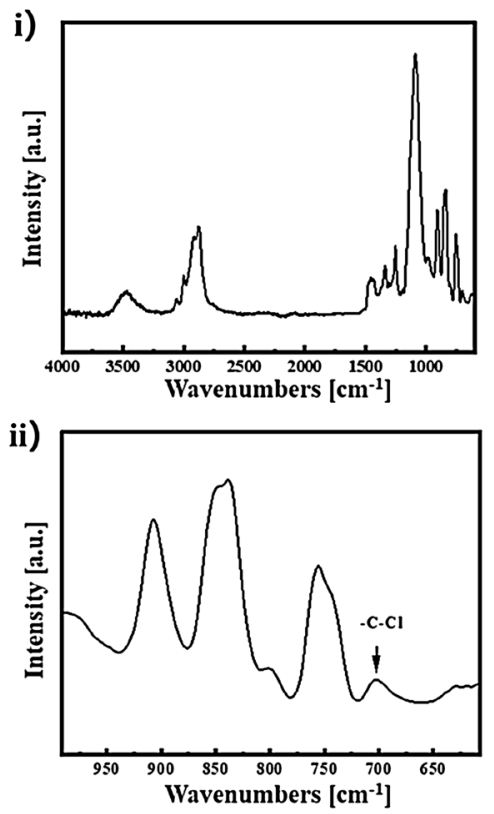

Fig. 3 Proposed mechanisms of chlorohydrin byproduct generation during GGE monomer production. (a) Reaction scheme showing potential byproducts, which could be formed during the synthesis of GGE monomer based on the reaction between glycerol and ECH.
Inactive $\mathrm{Cl}$ end groups were marked in red. (b) ATR-FT-IR spectrum of GGE monomer. i, spectrum in the range of $500-4000 \mathrm{~cm}^{-1}$; (ii), zoom-in spectrum in the range of $600-1000 \mathrm{~cm}^{-1}$ 
Results from total chloride and free chloride anion content determination also confirmed the presence of organochloride in GGE monomer $(0.0024 \pm 0.0002 \mathrm{wt} \%$ free chloride anion and $13.42 \pm 0.23 \mathrm{wt} \%$ total chloride). Moreover, two weeks solvent washing did not remove the organochloride in polyGGE $(13.75 \pm 0.73 \mathrm{wt} \%$ total chloride in crude polyGGE and $12.68 \pm 1.27 \mathrm{wt} \%$ in washed polyGGE, Table S1), which means these organochloride containing compounds were either chemically bound to the polymer structure or entrapped in the crosslinked network.

The swelling data showed that polyGGE was densely crosslinked with low $\overline{M_{n}}$ values $\left(29.4 \pm 1.0 \mathrm{~g} \cdot \mathrm{mol}^{-1}\right.$, Table S2) of the chain segments, indicating a highly branched polymer network. With such high crosslink density and low swelling ability, mono-functional or non-functional byproducts could be stabilized in the densely crosslinked network. As chlorohydrin molecules have a high polarity, they could alter plasma and mitochondrial membrane stability and permeability of the cells. It is likely that the released chlorohydrin molecules are taken up into L929 cells and cause the cell detachment, thereafter completing cell lysis [30]. Chloride binding to the backbone of the polymer network seems to have little negative effect on the cells. An example would be poly(vinyl chloride), which is actually used as biomaterials, e.g. for blood bags [31]. However, free organochlorides released from the bulk can cause the cell death [32].

The ATR-FT-IR spectra profile of the GGE monomer showed a weak C-H stretching of epoxide at $3056 \mathrm{~cm}^{-1}$, asymmetric epoxide ring deformation at $907 \mathrm{~cm}^{-1}$, symmetric epoxide ring deformation at $839 \mathrm{~cm}^{-1}$ and epoxide ring breathing at $1256 \mathrm{~cm}^{-1}$. In addition to that, the presence of peaks at $2998 \mathrm{~cm}^{-1}, 985 \mathrm{~cm}^{-1}$ (as a shoulder), $754 \mathrm{~cm}^{-1}$, $1337 \mathrm{~cm}^{-1}$ and $1452 \mathrm{~cm}^{-1}$ are also characteristics of cyclic ethers (Fig. 3bi) [33-35].

C-Cl stretching frequencies were observed at $701 \mathrm{~cm}^{-1}$ (Fig. 3bii), while broad absorbance from 3600 to $3300 \mathrm{~cm}^{-1}$ can be assigned to $-\mathrm{OH}$ stretching vibrations, which may result from the incomplete glycidylation of alcohol groups (Fig. 3bi).

\section{Conclusions}

The eluent from polyGGE films strongly impaired the cell viability, plasma membrane integrity and metabolic activity due to the unhydrolyzable organochloride byproducts or ECH precursors originating from the GGE monomer, which was explored by HPLC-ESI-MS. Chloride content determination and ATR-FT-IR analysis confirmed the presence of the organochloride in the monomer mixture and could not be fully extracted by solvent washing. Swelling data revealed that polyGGE was highly crosslinked and capable of trapping the unfavored byproducts. To this end, reducing the crosslink density might be a potential solution to achieve the goal of eliminating the cytotoxic substances from the proposed materials so that these purified materials could be used for biomedical applications.

Supplementary Information The online version contains supplementary material available at https://doi.org/10.1557/s43580-021-00132-y.

Acknowledgments We thank Angelika Ritschel, Karola Lützow and Hendrik Wetzel (FhG-IAP) for technical support of cytotoxicity test, HPLC-ESI-MS and chloride content analysis. This work was financially supported by the Helmholtz Association of German Research Centers (through program-oriented funding, Helmholtz Cross Program Initiative "Technology and Medicine Adaptive Systems", Helmholtz Virtual Institute, Multifunctional Biomaterials for Medicine (Grant No. VH-VI-423)) as well as the Federal Ministry of Education and Research, Germany, for funding through the Program Health Research (Grant No. 13GW0098).

Funding Open Access funding enabled and organized by Projekt DEAL.

Data availability Data will be made available on reasonable request.

\section{Declarations}

Conflict of interest The authors have no relevant financial or non-financial interests to disclose.

Open Access This article is licensed under a Creative Commons Attribution 4.0 International License, which permits use, sharing, adaptation, distribution and reproduction in any medium or format, as long as you give appropriate credit to the original author(s) and the source, provide a link to the Creative Commons licence, and indicate if changes were made. The images or other third party material in this article are included in the article's Creative Commons licence, unless indicated otherwise in a credit line to the material. If material is not included in the article's Creative Commons licence and your intended use is not permitted by statutory regulation or exceeds the permitted use, you will need to obtain permission directly from the copyright holder. To view a copy of this licence, visit http://creativecommons.org/licenses/by/4.0/.

\section{References}

1. F.G. Garcia et al., Epoxy networks for medicine applications: Mechanical properties and in vitro biological properties. J. Appl. Polym. Sci. 112(3), 1215-1225 (2009)

2. S. Groos, E. Reale, L. Luciano, Re-evaluation of epoxy resin sections for light and electron microscopic immunostaining. J. Histochem. Cytochem.. 49(3), 397-406 (2001)

3. Z. Mo et al., Mechanical properties of epoxy resin/PMMA/SiO dental composites. J. Test Eval. 43(1), 80-86 (2015)

4. T. Kim et al., Orthopedic implants and devices for bone fractures and defects: past, present and perspective. Eng. Regener. 1, 6-18 (2020)

5. C.S. Pundir et al., An amperometric cholesterol biosensor based on epoxy resin membrane bound cholesterol oxidase. Indian J. Med. Res. 136(4), 633-640 (2012) 
6. S. Schottler et al., Protein adsorption is required for stealth effect of poly(ethylene glycol)- and poly(phosphoester)-coated nanocarriers. Nat. Nanotechnol. 11(4), 372-377 (2016)

7. H.J. Busscher, R.J. Ploeg, H.C. van der Mei, SnapShot: biofilms and biomaterials; mechanisms of medical device related infections. Biomaterials 30(25), 4247-4248 (2009)

8. R.A. Al-Horani, U.R. Desai, Chemical sulfation of small molecules - advances and challenges. Tetrahedron 66(16), 2907-2918 (2010)

9. Y. Ma et al., The adverse health effects of bisphenol A and related toxicity mechanisms. Environ. Res. 176, 108575 (2019)

10. D. Ekinci, A.L. Sisson, A. Lendlein, Polyglycerol-based polymer network films for potential biomedical applications. J. Mater. Chem. 22(39), 21100-21109 (2012)

11. J.V. Crivello, Design and synthesis of multifunctional glycidyl ethers that undergo frontal polymerization. J. Polym. Sci. A Polym. Chem. 44(21), 6435-6448 (2006)

12. J. He et al., Chemical modification of Bombyx mori silk with calcium-salt treatment and subsequent glycerin triglycidyl ether crosslinking. J. Appl. Polym. Sci. 118(6), 3260-3268 (2010)

13. F. Ng et al., Bio-based aromatic epoxy monomers for thermoset materials. Molecules 22(1), 149 (2017)

14. B.M. Bell et al., Glycerin as a renewable feedstock for epichlorohydrin production. The GTE process. CLEAN 36(8), 657-661 (2008)

15. W.H. Lawrence et al., Toxicity profile of epichlorohydrin. J. Pharm. Sci. 61(11), 1712-1717 (1972)

16. W. Li, J. Zhou, Y. Xu, Study of the in vitro cytotoxicity testing of medical devices. Biomed. Rep. 3(5), 617-620 (2015)

17. T.J. Jentsch, Chloride channels are different. Nature 415(6869), 276-277 (2002)

18. Z. Tomaskova, K. Ondrias, Mitochondrial chloride channelsWhat are they for? FEBS Lett. 584(10), 2085-2092 (2010)

19. F. Zheng et al., Drp-1-dependent mitochondrial fragmentation contributes to cobalt chloride-induced toxicity in Caenorhabditis elegans. Toxicol. Sci. 177(1), 158-167 (2020)

20. Q. Liu et al., Organochloride pesticides impaired mitochondrial function in hepatocytes and aggravated disorders of fatty acid metabolism. Sci. Rep. 7, 46339 (2017)

21. H.E. Webel et al., Revealing cytotoxic substructures in molecules using deep learning. J. Comput. Aided Mol. Des. 34(7), 731-746 (2020)

22. J. Zhang, U. Norinder, F. Svensson, Deep learning-based conformal prediction of toxicity. J. Chem. Inf. Model 61(6), 2648-2657 (2021)
23. R.S. Suliman et al., Metabolites profiling, in vitro, in vivo, computational pharmacokinetics and biological predictions of aloe perryi resins methanolic extract. Plants 10(6), 1106 (2021)

24. V. Kasparkova et al., Exploring the critical factors limiting polyaniline biocompatibility. Polymers 11(2), 362 (2019)

25. J. Chevrier et al., Body weight loss increases plasma and adipose tissue concentrations of potentially toxic pollutants in obese individuals. Int. J. Obes. Relat. Metab. Disord. 24(10), 1272-1278 (2000)

26. V. Thomas, M. Jayabalan, A new generation of high flex life polyurethane urea for polymer heart valve-studies on in vivo biocompatibility and biodurability. J. Biomed. Mater. Res A 89(1), 192-205 (2009)

27. B.C. Kallukalam, M. Jayabalan, V. Sankar, Studies on chemically crosslinkable carboxy terminated-poly(propylene fumarate-coethylene glycol)-acrylamide hydrogel as an injectable biomaterial. Biomed. Mater. 4(1), 015002 (2009)

28. Y. Djoumbou-Feunang et al., CFM-ID 3.0: significantly improved ESI-MS/MS prediction and compound identification. Metabolites 9(4), 72 (2019)

29. G.F. White, N.J. Russell, E.C. Tidswell, Bacterial scission of ether bonds. Microbiol. Rev.. 60(1), 216-232 (1996)

30. M.C. Vissers, A.C. Carr, C.C. Winterbour, Fatty acid chlorohydrins and bromohydrins are cytotoxic to human endothelial cells. Redox. Rep. 6(1), 49-55 (2001)

31. L. Christenson, K.E. Dionne, M.J. Lysaght, Biomedical applications of immobilized cells, in Fundamentals of Animal Cell Encapsulation and Immobilization. ed. by M.F. Goosen (CRC Press, Boca Raton, 1993), pp. 7-41

32. M.J. Plewa et al., Mammalian cell cytotoxicity and genotoxicity of the haloacetic acids, a major class of drinking water disinfection by-products. Environ. Mol. Mutagen. 51(8-9), 871-878 (2010)

33. R. Soto, J. Freer, J. Baeza, Evidence of chemical reactions between di- and poly-glycidyl ether resins and tannins isolated from Pinus radiata D. Don bark. Bioresour. Technol. 96(1), 95-101 (2005)

34. G. Nikolic et al., Fast Fourier transform IR characterization of epoxy GY systems crosslinked with aliphatic and cycloaliphatic EH polyamine adducts. Sensors 10(1), 684-696 (2010)

35. A. Manakhov et al., Analysis of epoxy functionalized layers synthesized by plasma polymerization of allyl glycidyl ether. Phys. Chem. Chem. Phys. 20(30), 20070-20077 (2018) 